Volney de M. Câmara 2

Alexandre P. Silva 3

Fátima Pivetta 4

Maurício A. Perez 2

Maria Imaculada M. Lima 2

Maria Izabel de F. Filhote 2

Lidia Maria B. Tavares 5

MarcosV. Maciel 2

F. V. Alheira 2

T. Dantas 2

M. S. Martins 2

\section{Estudo dos níveis de exposição e efeitos à saúde por mercúrio metálico em uma população urbana de Poconé, Mato Grosso, Brasil 1}

\author{
Study of exposure to and health effects of \\ atmospheric metallic mercury pollution in an urban \\ population of Poconé, Mato Grosso, Brazil 1
}

1 Projeto financiado com recursos da Fundação GTZ (Alemanha) e Organização Panamericana da Saúde (Centro Panamericano de Ecologia Humana e Saúde) e Representação da OPAS no Brasil). Também pelo apoio da Prefeitura Municipal de Poconé, Mato Grosso.

2 Núcleo de Estudos de Saúde Coletiva, Universidade Federal do Rio de Janeiro. Av. Brigadeiro Trompowsky s/no, 5o andar (ala sul), Rio de Janeiro, RJ 21941-590, Brasil.

3 Centro de Tecnologia Mineral/CNPq. Cidade Universitária, Rio de Janeiro, RJ 21949-000, Brasil. 4 Centro de Estudos de Saúde do Trabal hador e Ecologia Humana, Escola Nacional de Saúde Pública, Fiocruz. Rua Leopoldo Bulhões 1480, Rio de Janeiro, RJ 21041-210, Brasil.

5 Instituto de Saúde Coletiva, Universidade Federal do Mato Grosso.

Av. Fernando Correira s/no Cuiabá, MT

78060-900, Brasil.
Resumo Foram avaliados os níveis de exposição e dos efeitos causados por emissões na atmosfera de mercúrio metálico proveniente de casas compradoras de ouro na população do Município de Poconé, Estado de Mato Grosso. O projeto foi desenvolvido através da comparação da morbidade referida, dos exames clínicos e da análise dos teores de mercúrio na urina de três grupos populacionais. As análises dos teores de mercúrio na urina mostraram di ferenças al tamente si gnificati vas entre os grupos centro e periferia em comparação ao grupo-controle. Entrevistas com as pessoas que apresentavam teores el evados evidenciaram que a exposição no centro da ci dade poderia ser proveniente das casas compradoras de ouro e, no caso da periferia, poderia ter ocorrido exposi ção através da quei ma de amál gamas no interior das resi dências. Os dados de morbidade referi da apresentaram proporções maiores de queixas entre os moradores do centro em comparação aos outros gru pos e também maior número de al terações no exame clínico. Conclui-se que há maiores exposi ção e efeitos à saúde devido ao mercúrio metálico entre pessoas pertencentes aos primeiros dois grupos.

Palavras-chave Mercúrio; Saúde Ambiental; Saúde Ocupacional; Ecologia Humana

Abstract This paper evaluates the levels of exposure to and health effects of metallic mercury emissions into the atmosphere by gold dealers in the town of Poconé, Mato Grosso State, Brazil. The project was based on the comparison of referred morbidity, clinical examination, and metallic mercury urinary concentrations in three population groups. The first group consisted of downtown resi dents who were exposed to metallic mercury emissions. The second group resided on the outskirts of the town and the third in an agri cultural area. Urinary concentrations of metallic mercury showed highly si gnificant differences between groups from downtown and the outskirts as compared to the control group. Investigation of individuals with high concentrations showed that exposure in the downtown area might have come from gol d deal ers' establishments. In the group from the town outskirts, exposure might have been from amalgam-smel ting done inside homes. Referred morbidity data showed an increased proportion of complaints and alterations in clinical examinations by downtown residents as compared to the other groups. It was concluded that there was a possibility of exposureand heal th effects caused by metallic mercury for resi dents from the first two groups.

Key words Mercury; Environmental Health; Occupational Health; Human Ecology 


\section{Introdução}

Os riscos dos processos produtivos, principalmente aqueles causados pelos agentes químicos, geralmente ultrapassam os limites da área física dos locais de trabalho. Esteé o caso da utilização do mercúrio em processos de produção de ouro no Brasil, cujos riscos e efeitos à saúde humana podem atingir populações tanto ocupacionais como não-ocupacionais. O processo produtivo do ouro causa a exposição direta dos trabalhadores ao mercúrio metálico nos ambientes de trabalho e a exposição indireta da população em geral que esteja próxima às áreas garimpeiras. O mercúrio metálico pode também sofrer um processo de metilação em sedimentos dos rios, contaminando os peixese causando um perigo potencial de exposição ao metil-mercúrio para toda a população.

O ouro encontrado sob a forma de pó exige o uso do mercúrio para formar um amálgama que facilita a sua identificação, geral mente na proporção de um quilo de ouro para um quilo de mercúrio (Pffeiffer, 1993; Couto, Câmara \& Sabrosa, 1988; Ferreira \& Appel, 1990). O amálgama ouro-mercúrio é posteriormente queimado, purificando o ouro e liberando mercúrio para a atmosfera. O ouro produzido no garimpo é comercializado em lojas em centros urbanos, onde é novamente queimado para purificação, liberando também mercúrio para a atmosfera.

A partir do processo de trabalho em áreas garimpeiras, pode-se categorizar os expostos em:

1) População ocupacionalmente exposta ao mercúrio metálico, incluindo os garimpeiros que queimam ouro, garimpeiros próximos às áreas de queima e funcionários de lojas que comercializam o ouro.

2) População em geral exposta ao mercúrio metálico, ou seja, pessoas próximas ao locais de garimpo e às lojas que comercializam o ouro.

3) População em geral ou ocupacional potencialmente exposta ao metil-mercúrio, abrangendo os consumidores de peixes.

A análise do processo produtivo não deixa dúvidas sobre a exposição ocupacional ao mercúrio metálico, que vem sendo comprovada através de publicações de autores como, por exemplo, Couto (1991), Gonçalves (1993) eTobar, Hacon \& Câmara (1990). Resultados de estudos em populações humanas sobre o terceiro grupo citado (expostos ao metil-mercúrio) ainda não podem caracterizar a dimensão do problema, embora alguns estudos mostrem dados preocupantes (Malm et al., 1990); (Hacon, 1990); (Câmara \& Corey, 1992). Todavia, ainda não foram publicados dados no Brasil sobre efeitos à saúde do grupo representado pela população em geral exposta ao mercúrio metálico, e as conclusões existentes se caracterizam por um perfil ambiental baseado pela concentração atmosférica a partir das lojas que comercializam ouro. O preenchimento desta importante lacuna foi o objetivo principal desta pesquisa. Buscou-se avaliar os níveis de exposição e efeitos à saúde entre residentes de área urbana expostos à poluição atmosférica pelo mercúrio metálico no Muncípio de Poconé - MT. Além deste projeto, está sendo concluído outro estudo sobre efeitos da poluição atmosférica para uma tese de doutoramento (Hacon, 1995) no Município de Alta Floresta, também no Estado de Mato Grosso.

Este estudo torna-se prioritário no momento atual porque o ouro, ao ser vendido nas casas compradoras, apresenta resíduos de 3 a $5 \%$ de mercúrio (CETEM/CNPq, 1994). Durante a purificação para pesagem esse teor residual é volatilizado, contaminando não somente o ambiente das lojas, como também toda vizinhança. A inexistência de sistemas adequados para a retenção do mercúrio nestas lojas, que dispõem, quando muito, de simples exaustores, resulta na contaminação atmosférica por mercúrio metálico do meio ambiente até um raio de cerca de 400 metros a partir dos pontos de queima, dependendo da predominância e intensidade dos ventos (Silva et al., 1991); CETEM/CNPq (1994). Marins et al. (1991) demonstraram que as operações de queima em centros urbanos devem ser controladas, pois nas proximidades de casas compradoras em Poconé, Mato Grosso, foram detectados teores acima de $1,65 \mu \mathrm{g} / \mathrm{m}^{3}$ de mercúrio no ar, ultrapassando o limite máximo permissível de 1,0 $\mu \mathrm{g} / \mathrm{m}^{3}$ (OMS, 1976).

O mercúrio é um metal de alta toxicidade. Penetra no organismo através de diferentes vias dependendo de sua forma físico-química. O mercúrio metálico é absorvido principal mente pela via respiratória, sendo parte depositada em tecidos, onde se conjuga com grupamentos sulfridrilas de proteínas (Galvão \& Corey, 1987). Pode causar intoxicação aguda, com predominância dos sinais e sintomas respiratórios e intoxicações subagudas e crônicas, afetando o sistema nervoso, rins e pele (ATSDR, 1989); (WHO, 1976); (WHO, 1991). A fração não absorvida é eliminada principal mente através da urina.

A escolha do Município de Poconé como área de estudo teve como principais critérios o fato deste estar situado em uma área de preservação ambiental, o Pantanal Matogrossense, e apresentar uma produção de ouro que pode 
ser caracterizada como estável ou até em ascensão. Segundo dados oficiais do Banco Central do Brasil adaptados pela METAMAT (1995), a quantidade de ouro produzida em Poconé cresceu de $1.855,1$ para 2.539,6 quilogramas (kg) entre os anos de 1990 a 1994, ao passo que a produção total do Estado de M ato Grosso decresceu (25.230,4 para $17.304,1$ kg), assim como a dos municípios de maior produção no Estado de Mato Grosso, como Peixoto Azevedo (de 7.266,2 para $4.540,1 \mathrm{~kg}$ ) e Alta Floresta (6.301,2 para 4.390,6 kg). No Brasil, a partir de 1970, a extração deste metal cresceu acentuadamente. Félix (1987) cita um crescimento de 9,6 toneladas em 1972 para 80,1 toneladas em 1986, e Hasse (1993) estimou para o ano de 1988 um total de 218,6 toneladas de ouro produzidas. Esta produção de ouro atingiu seu pico no biênio 89-90, sofrendo, após, um declínio causado pelo lançamento do Plano de Estabilização Econômica, editado em março de 1990, que aumentou em até cinco vezes os custos dos insumos básicos da produção e pela diminuição do preço do ouro no mercado internacional (Silva, 1993).

\section{Materiais e métodos}

Foi realizado um estudo epidemiológico comparativo do tipo seccional, com o objetivo de avaliar os níveis de exposição e dos efeitos do mercúrio metálico atmosférico em residentes da área urbana do Município de Poconé, Estado do M ato Grosso, expostos às emissões provenientes de casas compradoras de ouro. Desenvolveu-se um inquérito de morbidade referida, exame clínico simplificado e análise do teor de mercúrio na urina (subprojeto saúde). Os levantamentos ambientais incluíram a análise do teor de mercúrio em ar, solos e poeiras das moradias, peixes e provas do potencial de metilação (subprojeto meio ambiente). As análises ambientais ainda estão em fase de processamento e, neste artigo, serão apresentados os dados do componente saúde.

O Município de Poconé fica situado na Baixada Cuiabana, área rebaixada limitada a oeste, noroeste e norte pela Província Serrana, a leste pelo Planalto dos Guimarães e a sul pelo Pantanal Matogrossense. Do ponto de vista político-administrativo, a Baixada Cuiabana engloba também os Municípios de Acorizal, Rosário Oeste, Cuiabá, Livramento, Santo Antonio de Leverger, Várzea Grande e Barão de Melgaço. A população do Município de Poconé é de 29.705 habitantes, dos quais 21.185 em área urbana (IBGE, 1993). Na região de Poconé, a pecuária, além da mineração de ouro, é a atividade econômica mais desenvolvida. A atividade garimpeira nesta região remonta ao ano de 1716 com a descoberta das minas de ouro no rio Caxipó-Mirim (Silva et al., 1991).

Para desenvolvimento do projeto, pôs-se também em prática um estudo descritivo preliminar, através da observação, dados de registro e entrevistas, com o objetivo de obter informações sobre o processo de trabalho, relações de trabalho, condições de vida e dados de morbidade nos garimpos, e buscaram-se dados demográficos e de morbidade que serviram de base para o desenho do plano amostral.

Definiram-se como população a ser analisada os moradores do centro da cidade, local onde estão concentradas as lojas compradoras de ouro. Estas pessoas deveriam residir a até uma distância de 400 metros a favor dos ventos, tendo como base as lojas compradoras de ouro. Como citado anteriormente, os níveis de concentração atmosférica de mercúrio mostraram um gradiente de contaminação desde a fonte de emissão (lojas) até cerca de um raio de 400 metros. O tamanho amostral foi calculado em 196 pessoas, arredondado para 200. Amostras de 200 pessoas seriam capazes de detectar diferenças entre os grupos com uma potência de $80 \%$ e um erro primário de $5 \%$ (Fleiss, 1979). Estas pessoas foram sorteadas de casas listadas nos mapas censitários da Fundação Instituto Brasileiro de Geografia e Estatística (IBGE). Como população-controle, definiramse os habitantes de uma área agrícola próxima à área urbana, denominada Maravilha, onde não existe atividade garimpeira.

Não foi possível escolher uma outra área da cidade como controle pelo fato de em vários pontos da cidade existir a prática da busca de ouro nos terrenos das casas, que também causa exposição ao mercúrio metálico após a queima doméstica dos amálgamas. Na área central isto não ocorre porque concentra as atividades econômicas de administração da cidade e do comércio local.

Não ocorreram problemas para a coleta das amostras no centro da cidade, onde participaram 200 pessoas. Todavia, na área agrícola, foram encontradas apenas 41 pessoas e, por este motivo, foi definido um terceiro grupo populacional para comparação em um conjunto habitacional situado em área periférica da cidade denominado COHAB. As casas eram bastante semelhantes entre si, nível sócio-econômico inferior ao do centro, porém apresentando boas condições sanitárias. Na COHAB esperava-se uma exposição intermédiária entre os dois grupos já citados, uma vez que ficava a 
mais de 500 metros da última loja compradora, antes da rodovia de acesso a Cuiabá. Além disso, nos quintais das casas não existiam indícios de procura de ouro.

A COHAB contava com cinco ruas, sendo sorteadas duas delas, para o desenvolvimento do projeto. Todas as pessoas encontradas participaram da amostra, não havendo recusa.

O critério de inclusão das pessoas no estudo foi a idade acima de cinco anos, devido ao exame neurológico. Como critério de exclusão, a pessoa não deveria ter trabalhado em produção ou comércio de ouro ou outra atividade relacionada com o mercúrio, recentemente, isto é, em um período inferior a um ano, uma vez que interessava para o estudo os riscos da população residente, e não os dos expostos ocupacionalmente ao mercúrio.

Para cada pessoa era aplicado um questionário com as seguintes informações:

a) Dados gerais de identificação.

b) História ocupacional.

c) Condições de vida.

d) Morbidade geral.

e) Morbidade específica para mercúrio metálico.

f) Alcoolismo.

g) Consumo de peixe.

A variável alcoolismo foi avaliada através de quatro perguntas do questionário CAGE, validado em diversos estudos nacionais e internacionais (Masur \& Monteiro, 1983).

Realizou-se também um exame físico simplificado, direcionado para efeitos do mercúrio metálico, principalmente para o sistema nervoso e rins. Houve também a coleta de urina para análise dos teores de mercúrio. Foi solicitada apenas uma coleta, dada a impossibilidade de ser realizada a análise da urina de 24 horas.

O material (cerca de $50 \mathrm{ml}$ ) foi condicionado em frasco de polipropileno de boca larga e armazenado em freezer, a menos de $20^{\circ} \mathrm{C}$. A técnica analítica foi a da determinação de mercúrio total através da espectrofotometria por absorção atômica pela técnica do vapor frio. Esta análise ficou a cargo do Laboratório de Toxicologia do Centro de Estudos de Saúde do Trabal hador e Ecologia Humana (CESTEH) da Fundação Oswaldo Cruz, que mantém sistema de controle de qualidade e participa de programas de intercalibração.

A equipe de campo contou com três médicos, quatro estudantes de Medicina que já tinham participado de outro estudo sobre os efeitos do mercúrio, uma bióloga, uma enfermeira e psicóloga e uma assistente social. Os instrumentos e os procedimentos para exame clínico simplificado foram exaustivamente testados antes do estudo.
Os dados obtidos foram armazenados em microcomputador utilizando o programa EPIINFO (Dean et al., 1992). A análise estatística das diferenças entre os três grupos foi feita principalmente utilizando o teste do Qui-Quadrado (Fleiss, 1979 e Armitage, 1971), que é obtida comparando-se as freqüências esperadas de respostas corretas com as freqüências efetivamente observadas. Para a interpretação deste teste utilizou-se o valor da probabilidade mais conservador, ou seja, o Yates Corrected, e algumas vezes foram utilizados os Testes de Fisher (quando o valor esperado em qualquer célula da Tabela fosse menor que 5) e de Kruskal-Wallis (na impossibilidade de realizar o TesteT de student).

\section{Resultados}

A coleta dos dados ocorreu entre os dias 1 a 8 de julho de 1995. Participaram do estudo 200 pessoas do centro da cidade, 124 da área periférica e 41 da área agrícola, sendo esta última a partir de agora denominada de controle. Os resultados serão apresentados em três partes: identificação, exposição e efeitos.

Os dados de identificação

A Tabela 1 apresenta as variáveis de identificação dos grupos populacionais estudados. Em relação à média de idade, embora o teste de significância demonstre diferenças entre os três grupos ( $p \triangleleft 0,000$ ), não ocorreu diferença significativa entre os grupos da área central e controle $(p=0,14)$ e também entre os grupos da área periférica e controle $(p=0,25)$. O mesmo ocorreu com a variável sexo, respectivamente $(p=0,91)$ e $(p=0,16)$. A não-existência de diferenças estatisticamente significantes entre os grupos indicou que, pelo menos para as duas variáveis mais importantes (sexo e idade), a comparabilidade dos grupos poderia ser realizada.

Quanto à renda familiar, o fato de o grupocontrole apresentar uma renda mais baixa, o que significaria até uma maior possibilidade de acometimento de problemas de saúde, poderia valorizar os resultados positivos de morbidade nos outros grupos.

A única limitação encontrada para a comparação entre os grupos foi representada pela escolaridade. Em que pese ser elevada a presença de analfabetos e pessoas com apenas o primeiro grau incompleto em todos os grupos, a diferença é significativa entre os grupos centro $(p<0,000)$ e periferia $(p=0,04)$ em relação ao grupo-controle, mostrando que pode ter havido diferença na capacidade de entender e res- 
Variáveis de identificação por grupos populacionais estudados. Poconé, MT, 1995.

\begin{tabular}{|c|c|c|c|c|c|c|c|}
\hline & Centro (A) & Periferia (B) & Controle (C) & (p) & $(p A C)$ & $(p B C)$ & $(p A B)$ \\
\hline Média de idade & 36,6 & 25,5 & 32,7 & $(<0,000)$ & $(0,14)$ & $(0,25)$ & $(<0,000)$ \\
\hline Sexo Masculino & $58,0 \%$ & $71,8 \%$ & $58,5 \%$ & $(0,03)$ & $(0,91)$ & $(0,16)$ & $(0,01)$ \\
\hline Feminino & $42,0 \%$ & $28,2 \%$ & $41,5 \%$ & - & - & - & - \\
\hline Renda $<1$ S.M. & $14,1 \%$ & $30,8 \%$ & $50,0 \%$ & $(<0,000)$ & $(<0,000)$ & $(0,06)$ & $(<0,000)$ \\
\hline $\begin{array}{l}\text { Analfabetos ou } \\
\text { 1o grau incompleto }\end{array}$ & $68,3 \%$ & $88,5 \%$ & $100,0 \%$ & $(<0,000)$ & $(<0,000)$ & - & - \\
\hline
\end{tabular}

Probabilidade através do teste de Kruskal-Wallis para idade e Qui-quadrado para demais variáveis.

Tabela 2

Medidas descritivas dos teores de mercúrio na urina em g/l por grupos populacionais estudados. Poconé, MT, 1995.

\begin{tabular}{|c|c|c|c|}
\hline & Centro $(A)$ & Periferia (B) & Controle (C) \\
\hline Número de amostras & 158 & 117 & 41 \\
\hline Média & 4,35 & 4,89 & $<1,25$ \\
\hline Variância & 121,70 & 129,38 & 0,09 \\
\hline Desvio Padrão & 11,03 & 11,37 & 0,31 \\
\hline Mínimo & $<1,2$ & $<1,2$ & $<1,2$ \\
\hline Percentil 25\% & $<1,2$ & $<1,2$ & $<1,2$ \\
\hline Mediana & $<1,2$ & $<1,2$ & $<1,2$ \\
\hline Percentil 75\% & 3,3 & 2,9 & $<1,2$ \\
\hline Máximo & 102,40 & 86,0 & 3,2 \\
\hline $\mathrm{N} \underline{\mathrm{o}}$ de amostras $>10 \mu \mathrm{g} / \mathrm{l}$ & 14 & 13 & - \\
\hline
\end{tabular}

Probabilidade através do teste de Kruskal-Wallis=23,0; $p<0,000 ;(A C)=22,8 ; p<0,000 ;(B C)=19,7 ; p<0,000$; $(A B)=0,15 ; p=0,69$.

ponder as perguntas. Isto significa que não haveria problemas para as comparações dos dados de exposição e dos exames clínicos, porém deveriam ser analisados com cautela os dados referentes à morbidade referida.

Não ocorreram diferenças significativas em outras variáveis estudadas que poderiam causar viés na interpretação dos resultados, e que foram: trabalho prévio em outro garimpo $(p=$ $0,27)$; trabalho prévio com mercúrio $(p=0,71)$; procura domiciliar de ouro $(p=0,65)$; e alcoolismo $(p=0,41)$. Não ocorreram diferenças entre consumo de peixe entre os grupos centro e controle $(p=0,87)$ e periferia e controle $(p=$ $0,20)$. A maioria das pessoas relatou que não costumava se alimentar de peixes (respectivamente $87,2 \%, 95,2 \%$ e $87,8 \%$ nos três grupos). A presença de amálgamas dentários também foi pesquisada, porém foi descartada para análise, devido à dificuldade de identificação por parte da equipe do projeto (não incluía odontólogos) e o número expressivo de pessoas que não possuíam dentes.
Os dados de exposição ao mercúrio

Na Tabela 2, observam-se as medidas descritivas das análises dos teores de mercúrio na urina em $\mu \mathrm{g} / \mathrm{I}$ nos grupos estudados, revelando uma média de 4,35 $\mu \mathrm{g} /$ I no centro, 4,89 $\mu \mathrm{g} /$ I na periferia e apenas 1,25 $\mu \mathrm{g} / \mathrm{I}$ na área-controle. A diferença entre os grupos centro e periferia em relação ao controle foi altamente significante $(p<0,000)$ ao Teste de Kruskal-Wallis. Embora a amostra fosse pequena no grupo controle, a pequena variância dos seus resultados contribuiu para que esse número fosse suficiente. $\mathrm{N}$ ão ocorreram diferenças significativas entre os grupos centro e periferia.

É importante assinalar que até a mediana, todos os grupos apresentavam o mesmo valor (menos de 1,2 $\mu \mathrm{g} / \mathrm{I}$ ), ou seja, o limite de detecção do método analítico, diferindo no percentil $75 \%$ e alcançando $102,4 \mu \mathrm{g} / \mathrm{I}$ no centro, 86,0 $\mathrm{mg} / \mathrm{I}$ na periferia e apenas 3,2 na área-controle. 
Os níveis médios de mercúrio na urina encontrados em populações não-expostas estão abaixo de $10 \mu \mathrm{g} / \mathrm{l}$ e, portanto, as médias das áreas central e periférica não estão elevadas (Alessio et al., 1993); (Pivetta et al., 1995); (Minoia et al., 1990); (Carvalho et al., 1993). Todavia, torna-se preocupante o fato destas médias estarem quase quatro vezes maiores que a apresentada na área sem exposição (controle).

Do mesmo modo, a existência de 14 pessoas no centro e 13 na periferia apresentando teores acima de $10 \mu \mathrm{g} / \mathrm{l}$ pode demonstrar a ocorrência de exposição ao mercúrio nestas duas áreas e a necessidade de ser realizada uma investigação mais detalhada das possíveis causas de tal exposição por parte destas pessoas que apresentam teores elevados, o que foi feito em uma outra ida a campo.

No grupo do centro, foram localizadas 13 das 14 pessoas. Todas foram entrevistadas e em apenas um caso houve relato de exposição ao mercúrio através da queima de amálgama realizada anteriormente na própria residência. As outras pessoas não relataram nenhum tipo de exposição ao mercúrio e, por exclusão, deduziu-se que esta exposição poderia ter ocorrido devido à proximidade das lojas compradoras de ouro. Foram pesquisadas exposições pregressas (último ano), levando-se em conta locais de trabalho próximos a áreas de queima de mercúrio, tratamento dentário ou moradia perto de consultório dentário, uso de pinturas no cabelo e cosméticos, uso de medicamentos, exposição ocupacional, etc. Vale acrescentar que os teores de mercúrio na urina refletem exposições recentes, uma vez que o mercúrio apresenta-se na urina durante a sua vida média no sangue.

Nas entrevistas realizadas na área da periferia, que surpreendentemente apresentou a média de teores de urina mais elevada, chamou a atenção o fato de oito, das 12 pessoas com teor de urina acima de $10 \mu \mathrm{g} / \mathrm{I}$, residirem em apenas três casas, tratando-se de três famílias. Nas entrevistas realizadas com as 13 pessoas, foram repetidos os mesmos procedimentos utilizados com o grupo em estudo e todas relataram queima, no fogão da casa, de amálgama ouromercúrio, trazido dos garimpos por algum parente. Tendo em vista a distância acima de 400 metros das lojas compradoras de ouro e o relato destas pessoas, pode-se inferir que a exposição na área periférica poderia ter ocorrido através da queima domiciliar do amálgama ouro-mercúrio. Poconé tem um clima muito quente e, possivelmente, o mercúrio retido nas paredes e em outras partes das casas poderia elevar a exposição a todos os residentes.

\section{Os dados de efeitos à saúde}

Em relação aos sintomas gerais referidos (Tabela 3), o grupo do centro foi o que apresentou maior proporção de queixas; porém, apenas para gosto metálico $(p \varangle 0,01)$ e irritação ocular $(p \triangleleft 0,01)$ houve diferenças estatisticamente significativas entre este grupo e o grupo-controle, e alergia na pele $(p=0,01)$ e dispnéia $(p=0,03)$ em relação aos dois grupos. As outras variáveis também relatadas em maior proporção, porém sem diferença estatística, foram: inflamação oral, sangramento oral, náuseas e suor excessivo. Do mesmo modo, o grupo da área-controle apresentou maior proporção de queixas (sem diferença estatística) para as variáveis inapetência, sialorréia, amolecimento dos dentes, zumbidos no ouvido e vômitos. No grupo da periferia, prevaleceu apenas a queixa de cefaléia, em proporção quase igual aos demais.

No caso dos relatos de sintomas de al teração do sistema nervoso (Tabela 4), a proporção

Tabela 3

Relato de sintomas gerais por grupos populacionais estudados. Poconé, MT, 1995.

\begin{tabular}{lccccc}
\hline & Centro (A) & Periferia (B) & Controle $(C)$ & $(p)$ & $(p A C)$ \\
\hline Inapetência & 15,5 & 12,9 & 26,8 & $(0,10)$ & $(0,12)$ \\
Inflamação oral & 10,0 & 6,5 & 0,0 & $(0,07)$ & $(0,07)$ \\
Sialorréia & 13,6 & 11,3 & 25,0 & $(0,09)$ & $(0,11)$ \\
Alergia na pele & 30,5 & 21,0 & 10,0 & $(0,01)$ & - \\
Gosto metálico & 9,0 & 8,2 & 5,0 & $(0,70)$ & $(0,01)$ \\
Irritação ocular & 40,5 & 30,6 & 22,5 & $(0,04)$ & $(0,04)$ \\
Dispnéia & 29,0 & 20,2 & 12,2 & $(0,03)$ & - \\
\hline
\end{tabular}

Probabilidade através dos Testes $\mathrm{Q}$ ui-Q uadrado e Fisher.

Cefaléia $(p=0,86)$; sangramento oral $(p=0,62)$; amolecimento dos dentes $(p=0,34)$.

Zumbidos no ouvido $(p=0,16)$; vômitos $(p=0,52)$; náuseas $(p=0,86)$; suor excessivo $(p=0,76)$. 
no grupo do centro foi maior para a grande maioria das variáveis, sendo esta diferença significativa em comparação ao grupo-controle para nervosismo $(p=0,02)$, ansiedade $(p=0,01)$, perda da calma $(p=0,006)$, perda de interesse $(p=0,02)$, dificuldade para tomar decisão $(p=$ $0,001)$, alteração da letra $(p=0,006)$ e astenia $(p \nless 0,000)$. Ocorreram diferenças significativas comparadas entre os dois grupos para perda da memória $(p=0,03)$, dificuldade para dormir $(p=$ $0,01)$, tremores $(p=0,03)$ e tremores nas mãos $(p=0,01)$. O grupo do centro apresentou menor proporção, sendo esta diferença não-significa- tiva em apenas duas variáveis: tremores nos lábios e nas pernas. Sobre os relatos de acometimento renal, não foram encontradas diferenças si gnificativas entre os grupos para as variáveis urina espumosa, urina escura e dificuldade para urinar, com excessão apenas para polaciúria $(p=0,01)$.

Estes resultados devem ser vistos com certa reserva, uma vez que existem, como citado anteriormente, diferenças relacionadas com a escolaridade que poderiam ter contribuído eles.

O exame físico simplificado ( Tabela 5) foi direcionado quase que exclusivamente para o

Tabela 4

Relato de sintomas de alteração do sistema nervoso por grupos populacionais estudados. Poconé, MT, 1995.

\begin{tabular}{|c|c|c|c|c|c|c|c|}
\hline & Centro $(\mathrm{A})$ & Periferia (B) & Controle $(\mathrm{C})$ & (p) & $(p A C)$ & $(p B C)$ & $(p A B)$ \\
\hline N ervosismo & 60,6 & 46,3 & 40,0 & $(0,008)$ & $(0,02)$ & $(0,61)$ & $(0,01)$ \\
\hline Ansiedade & 53,4 & 35,3 & 30,8 & - & $(0,01)$ & $(0,74)$ & $(0,003)$ \\
\hline Perda da calma & 50,8 & 39,7 & 25,6 & $(0,001)$ & $(0,006)$ & $(0,16)$ & $(0,07)$ \\
\hline Raiva & 18,7 & 21,3 & 7,7 & $(0,15)$ & $(0,14)$ & - & - \\
\hline Perda de interesse & 22,4 & 9,2 & 5,3 & $(0,001)$ & $(0,02)$ & $(0,66)$ & $(0,004)$ \\
\hline $\begin{array}{l}\text { Dificuldade para } \\
\text { tomar decisões }\end{array}$ & 36,3 & 23,7 & 7,9 & $(<0,000)$ & $(0,001)$ & $(0,05)$ & $(0,02)$ \\
\hline Perda da memória & 42,7 & 30,6 & 26,3 & $(0,03)$ & $(0,08)$ & $(0,76)$ & - \\
\hline Dificuldade para dormir & 24,0 & 11,3 & 22,0 & $(0,01)$ & $(0,93)$ & $(0,14)$ & $(0,007)$ \\
\hline Alteração da letra & 17,3 & 8,2 & 0,0 & $(0,006)$ & $(0,02)$ & $(0,23)$ & $(0,04)$ \\
\hline Parestesia & 25,3 & 17,3 & 15,0 & $(0,14)$ & $(0,23)$ & - & - \\
\hline Astenia & 44,0 & 24,4 & 22,0 & $(<0,000)$ & $(0,01)$ & - & - \\
\hline Tremores & 22,5 & 11,3 & 14,6 & $(0,03)$ & $(0,36)$ & $(0,76)$ & $(0,01)$ \\
\hline Tremores nas mãos & 20,1 & 8,1 & 12,2 & $(0,01)$ & $(0,33)$ & $(0,53)$ & $(0,005)$ \\
\hline
\end{tabular}

Fraqueza muscular $(p=0,55)$; tremores nas pernas $(p=0,84)$; tremor labial $(p=0,57)$; tristeza $(p=0,68)$; sonolência $(p=0,16)$. Probabilidade através dos testes Qui-quadrado e Fisher.

Tabela 5

Alterações no exame físico por grupos populacionais estudados. Poconé, MT, 1995.

\begin{tabular}{|c|c|c|c|c|c|c|c|}
\hline & Centro (A) & Periferia (B) & Controle (C) & (p) & $(p A C)$ & $(p B C)$ & $(p A B)$ \\
\hline Lesão de pele & 16,5 & 8,9 & 24,4 & $(0,03)$ & $(0,32)$ & $(0,02)$ & $(0,07)$ \\
\hline Edema de MMII & 7,5 & 1,6 & 2,4 & (NS) & $(0,20)$ & $(0,57)$ & $(0,04)$ \\
\hline Edema Periorbital & 10,5 & 3,2 & 2,4 & (NS) & $(0,08)$ & $(0,63)$ & $(0,02)$ \\
\hline Conjuntivas Eritematosas & 12,0 & 8,1 & 2,4 & (NS) & $(0,04)$ & $(0,19)$ & $(0,34)$ \\
\hline Tremor postural & 21,0 & 8,9 & 4,9 & $(0,001)$ & $(0,20)$ & $(0,32)$ & $(0,006)$ \\
\hline Tremor palpebral & 26,5 & 26,0 & 14,6 & $(0,26)$ & - & - & - \\
\hline Tremor de intenção & 13,1 & 13,1 & 4,9 & (NS) & - & - & - \\
\hline Romberg positivo & 16,6 & 3,4 & 5,3 & (NS) & $(0,12)$ & $(0,45)$ & $(0,000)$ \\
\hline Prova dedo-nariz positiva & 5,5 & 3,2 & 0,0 & (NS) & - & - & - \\
\hline Reflexo patelar diminuído & 10,9 & 9,0 & 3,0 & (NS) & - & - & - \\
\hline Reflexo bicipital diminuído & $0 \quad 5,4$ & 5,1 & 0,0 & (NS) & - & - & - \\
\hline
\end{tabular}

O utras variáveis não significativas: Ulcerações orais, tremor labial, disdiadococinesia, prova calcanhar-joelho e testes de sensibilidade tátil e dolorosa, Probabilidade $(p)$ através de cálculo Qui-quadrado (Yates corrected) e teste Fisher (1-tailed), NS = Não significante no teste de Fisher. 
sistema nervoso e rins. O grupo do centro apresentou mai or proporção de anormalidades para edema de membros inferiores, edema periorbitral, ulcerações orais, tremor labial, tremor palpebral, tremor de intenção, prova dedo-nariz, teste de sensibilidade tátil, reflexo patelar e reflexo bicipital, embora estas diferenças não tenham sido estatisticamente significativas; tais diferenças foram encontradas apenas para tremor postural $(p=0,001)$ e conjuntivas eritematosas $(p=0,04)$, além do Teste de Romberg em comparação com o grupo da periferia ( $p \lessdot 0,000)$.

Vale ressaltar que o grupo-controle apresentou mais anormalidades ao exame de pele $(p=0,03)$, e a tomada da pressão arterial apresentou média bastante semelhante entre os grupos para a pressão sistólica (respectivamente 127,5; 122,0 e 123,4 mmHg) e também diastólica (81,8; 82,3 e 82,3 mmHg).

Pode-se afirmar que, no caso do exame físico, pelo menos para algumas variáveis, tais como tremor palpebral e tremor de intenção, o tamanho da amostra do grupo-controle deve ter contribuído para que outras diferenças estatísticas não ficassem evidentes, apesar de o grupo controle ter incluído toda a população rural que residia próxima a Poconé.

\section{Conclusões}

Os dados de exposição mostram um padrão diferente das populações do centro e da periferia em relação ao grupo que reside em uma área sem atividade garimpeira. Além disso, a existência respectivamente de 14 e 13 pessoas nos grupos do centro e periferia apresentando teores de mercúrio acima de $10 \mu \mathrm{g} / \mathrm{I}$ e alcançando

\section{Agradecimentos}

Os autores agradecem a algumas pessoas que contribuíram decisivamente para o sucesso deste trabaIho: Dr. Rob McConnell e equipe (ECO/OPS); Dr. Luis Galvão, idealizador do projeto (HPE/OPS); Dra. Jacira Censio (Repres. OPS/Brasil); Profa. Carmem Asmus, Profa. Marisa Palácios, Dr. Ronaldo A. Santos, Profa. Silvia Vargas e Dra. Zina P. Oziel (UFRJ); Maria de Fátima Moreira e Fernanda C. Rosa (CESTEH/ Fiocruz) e Prof. Euclides Santos, Dr. Amanto Quinto de Souza, Dr. Ademar R. Prado, Sr. Antonio F. da Silva, Sr. Antonio A. Soares, Sra. IIma Regina F. Arruda, Sra. Maria de Lourdes A. Freitas e Sra. Marinalva Proença (Prefeitura Municipal de Poconé).
102,4 $\mu$ g/ I é preocupante. A não-identificação de outros pontos de exposição ao mercúrio por parte das pessoas leva a supor que esta maior exposição pode estar associada às emissões provenientes das casas compradoras de ouro na área do centro de Poconé. Quanto ao grupo da periferia, existem evidências de que se trata de poluição domiciliar através da queima de amálgamas trazidos dos locais de extração de ouro. Todos estes resultados podem vir a ser reforçados quando forem obtidos os dados ambientais que estão sendo concluídos. Além destes dados ambientais, estão sendo realizados novos estudos com uma segunda coleta de urina e a relação dos efeitos com os níveis de exposição ambiental .

As informações sobre o relato de problemas de saúde e o exame físico mostraram uma maior proporção de anormalidades na área do centro, quando comparada com as outras áreas, sugerindo que poderia estar relacionada à poluição atmosférica pelo mercúrio metálico.

Neste momento, torna-se prioritária a intervenção, uma vez que a situação em termos de contaminação ainda não parece ser grave. Para a área do centro, poderiam ser utilizadas soluções técnicas existentes e economicamente viáveis de implantação, como, por exemplo, o sistema acoplado de capela com exaustão forçada e lavador de gases. No caso da área da periferia, devem ser desenvolvidos programas de educação para saúde que discutam o risco da queima de amálgamas intradomiciliar. Evidentemente estas medidas de intervenção devem ser seguidas de uma avaliação do impacto para o ambiente e para a saúde da população através da análise dos teores de mercúrio na urina e da avaliação clínica, configurando um possível estudo epidemiológico do tipo Coorte.

\section{Referências}

ALESSIO, L.; CRIPPA, M., \& LUCCHINNI, R., 1993. Criteria document for occupational exposure limit values - Inorganic mercury. Ispra: Joint Research Center, CRC.

ATSDR (Agency for Toxic Substances and Disease Registry), 1989. Toxicological profilefor mercury. Atlanta, GA. U.S. Public Health Service.

ARMITAGE, P., 1971. Statistical Methods in Medical Re search. Oxford: Blackwell Scientific Publication.

CÂMARA, V. de M., 1992. Epidemiologia e Meio Ambiente: O Caso dos Garimpos de Ouro no Brasil. Metepec: Centro Panamericano de Ecologia Humana e Saúde (ECO/OPS). 
CÂMARA, V. de M., 1993a. Mercúrio em Áreas de Garimpos de Ouro. Série Vigilância 12, Metepec: Centro Panamericano de Ecologia Humana e Saúde (ECO/OPS).

CARVALHO, W. A., ONOFRE, C. R. E., MENEZES, G. A.; MONTE, L .S. \& DORIGATTI, F., 1993. Valores de referência de mercúrio urinário em uma amostra da população da cidade de Salvador - BA. Revista Brasileira de Toxicologia, 6 (Suplemento).

CETEM (Centro de Tecnologia Mineral) / CNPq (Conselho Nacional de Pesquisa), 1994. Desenvolvimento de tecnologia ambiental. Mercúrio em Itaituba. Rio de Janeiro: Centro de Tecnologia Mineral. (Mimeo.).

COUTO, R. C. de S., CÂM ARA, V. de M. \& SABROSA, P. C., 1988. Intoxicação mercurial: resultados preliminares em duas áreas garimpeiras - PA, Brasil. Cadernos de SaúdePública 4:301-315.

COUTO, R. C. de S., 1991. Buscando o ouro - perdendo saúde: Um estudo sobre as condições de saúde no garimpo do Cumaru. Tese de Mestrado, Rio de Janeiro: Escola Nacional de Saúde Pública, Fundação Oswaldo Cruz.

DEAN A. G., DEAN J. A., BURTON A. H. \& DICKER R. C., 1992. Epi Info, versión 5. A word processing, database and statistics system for epidemiology with Microcomputers. Atlanta: Center for Diseases Control and World Health Organization.

DNPM (Departamento Nacional de Produção Mineral), 1993. Levantamento nacional dos garimpeiros. Brasília: Relatório Analítico, Ministério da Infra-Estrutura. Série Tecnologia Mineral 45.

FÉLIX, J. T., 1987. Análise da produção de ouro no Brasil. Brasil Mineral, 48:90-96.

FERREIRA, R. H. \& APPEL, L. E., 1990. Mercúrio: Fontes e Usos. In: Resumos técnicos do projeto de senvolvimento de tecnologia ambiental no garimpo de ouro de Poconé(Villas-Boas, R. G., org.), pp. 16. Rio de Janeiro: Centro de Tecnologia Mineral/ CNPq. (Mimeo.).

FLEISS, J., 1979. Statistical methods for rates and proportions. New York: John Wiley and Sons.

GALVÃO, L. A. C. \& COREY, G., 1987. Mercurio. SerieVigilancia 7, Metepec: Centro Panamericano de Ecología Humana y Salud, OPS/ OMS.

GONÇALVES, A., 1993. Saúde, garimpagem e mercúrio entre os Kayapó-Gorotire. In: Conseqüências da garimpagem no âmbito social eambiental da Amazônia. (A. Mathis \& R. Rehaag, eds.), pp. 61-63, Belém: Fase, Buntistift \& Katalyse.

HACON, S., 1990. Contaminação por mercúrio na Amazônia. Documento elaborado para o Ministério da Saúde e a Organização Panamericana da Saúde, Brasília. (Mimeo.).

HACON, S., 1995. Avaliação do risco potencial para a saúde humana da exposição ao mercúrio na área urbana de Alta Floresta - MT. Tese de doutoramento, Rio de Janeiro: Universidade Federal Fluminense. No prelo.

HASSE, R. F., 1993. A comercialização de mercúrio no Brasil. In: Conseqüências da Garimpagem no Âmbito Social e Ambiental da Amazônia. (A. Mathis \& R. Rehaag, eds.), pp. 77-94, Belém: Fase, Buntistift \& Katalyse.

IBGE. (Fundação Instituto Brasileiro de Geografia e Estatística), 1993. Sinopse Preliminar do Censo Demográfico - 1991. Mato Grosso: IBGE.
MALM, O.; PFEIFFER, W.; SOUZA, C., M., M. \& REU THER, R., 1990. Mercury pollution due to gold mining in the Madeira River basin, Brazil. Ambio, 19:11-15.

MARINS, R. V.; IMBASSAHY, J. A.; PFEIFFER, W. \& BASTOS, W. R., 1991. Estudo preliminar da contaminação atmosférica por mercúrio em área produtora de ouro na cidade de Poconé. In: Poconé: Um Campo de Estudos do Impacto Ambiental do Garimpo,(Villas-Boas, R. C., ed.), pp. 85-93. Rio de Janeiro: Centro de Tecnologia Mineral/CNPq.

MASUR, J. \& MONTEIRO, G. M., 1983. Validation of the CAGE alcoholism screening test in a Brazilian psychiatric hospital setting. Brazilian Journal of Medical and Biological Research, 16:215-8.

METAM AT (Companhia Matogrossense de Mineração), 1995. Governo do Estado de Mato Grosso. Produção Regional de Ouro. (Mimeo.).

MINOIA, C.; SABBIONI, E.; APOSTOLI, P.; PIETRRA, R; POZZOLI, L.; GALIRINI, M.; NICOLAU, G.; ALESSIO, L. \& CAPODAGLIO, E., 1990. Trace element reference values in tissuesfrom inhabitants of the European Community. A study of elements in urine, blood and serum of healthly subjects. Science of Total Environment, 95:89-105.

PIVETTA, F. R.; FERREIRA, H. P. \& BARROCAS, P. R., 1995. Mercúrio no meio ambiente e seus efeitos à saúde humana. Rio de Janeiro: Editora Fiocruz (no prelo).

PFEIFFER, W. C., 1993. O controle da poluição ao mercúrio nos garimpos de ouro. In: Mercúrio em áreas de garimpos de ouro (V. de M. Câmara, ed.), pp. 129-138. Série Vigilância 12, Metepec: Centro Panamericano de Ecologia Humana e Saúde (ECO/OPS).

SILVA, A. P.; SI LVA, E. C. OLIVEIRA, E. F.; SILVA, G. D.; PADUA, H. B.; PEDROSO, L. R. M. \&VEIGA, M. M., 1991. Estudos Biogeoquími cos Sobre o Mercúrio em Ambi entes Aquáti cos de Poconé (Silva, A. P., ed.). Rio de Janeiro: Desenvolvimento de Tecnologia Ambiental. CETEM/CNPq.

SILVA, A. P., 1993. As diversas formas de garimpos de ouro, suas emissões de mercúrio e mecanismos de dispersão nos diversos compartimentos ambientais. In: Conseqüências da garimpagem no âmbito social eambiental da Amazônia (A. Mathis \& R. Rehaag, eds.), pp. 48-56. Belém: Fase, Buntistift \& Katalyse.

TOBAR, C.; HACON, S. \& CÂM ARA, V. de M., 1991. Município de Alta Floresta. Pré-diagnóstico da situação de saúde da população e de grupos ocupacionalmente expostos. Rio de Janeiro: Centro de Estudos de Saúde do Trabalhador e Ecologia Humana/ Fiocruz, 1991. Mimeo.

WHO (WORLD HEALTH ORGANIZATION), 1976. Mercury. Environmental Health Criteria, vol. 1. Geneva: WHO.

WHO (WORLD HEALTH ORGANIZATION), 1991. Inorganic Mercury.Environmental Health Criteria, vol. 118. Geneva: WHO. 